\title{
Cultivating a Global Perspective through Refugee Narratives
}

\author{
Michael T. MacDonald*
}

$06 / 20 / 2018^{\dagger}$

\begin{abstract}
The intention of this assignment is to use stories of refugee experience to cultivate a global perspective in the classroom. The final project of an intermediate college writing course (sophomore and junior level), this assignment asked students to research a topic related to refugee resettlement, apply ideas from course readings to that topic, and reflect on their own perspectives as readers and writers. This writing took the form of a textual analysis essay that combined primary and secondary sources grounded in library research. An emphasis on close-reading and rhetorical analysis provided students with strategies for moving between different modes of literacy (i.e. storytelling, theory, and reflection). The assignment was scaffolded throughout the semester by diverse readings that included memoir, journalist accounts, and scholarship in refugee studies. Although cultivating a global perspective with students was a central learning outcome of this assignment, the term proved difficult to define. This essay discusses how working with student writing provided some clarity on what a global perspective can mean.
\end{abstract}

Narratives about refugee experience are subject to audience expectations that construct the refugee as an object of aid, pity, and suspicion (MacDonald, 2015; Malkki, 1996). For example, readers might feel sympathy for those described as suffering. They might be shocked by the use of child soldiers. Or, they might express feelings of hope after learning about a protagonist's perseverance. Sometimes, readers might even be moved to action (see Boltanski, 1999; Chouliaraki, 2006). Nowhere are audience expectations made clearer than in this oft-quoted passage from Dave Eggers' (2007) What is the What, a novel about the Lost Boys of Sudan. As the narrator puts it, "Survivors tell the stories the sympathetic want, and that means making them as shocking as possible" (p. 21). In this sense, stories reflect a tension that persists in humanitarian work more

\footnotetext{
${ }^{*}$ Department of Language, Culture, and Communication, University of Michigan-Dearborn, mikemacd@umich.edu. Copyright 2018 Michael T. MacDonald. This work is licensed under a Creative Commons Attribution-NonCommercial 4.0 International License (http://creativecommons.org/licenses/by-nc/4.0/).

${ }^{\dagger}$ Submitted, 05/05/2017; Accepted, 01/24/2018.
} 
broadly: Humanitarian organizations have been both "celebrated as heroes" and derided as "pornographers of death" (Barnett \& Weiss, 2008, p. 6), and this reflective essay explores how that tension affects student writing on refugees. At first, I was suspicious of these kinds of audience expectations, of the deeply embedded cultural tropes surrounding published stories of refugee experience. But, I felt that I could make use of such responses to cultivate a "global perspective" with students. Results were mixed. On the one hand, student writing that reproduced some of these audience assumptions prompted more reflection on the ways I scaffolded the assignment. On the other, the assignment encouraged students to engage critically with representations of the Other and pushed them to examine their own habits as readers.

The assignment shared here was the final project in an intermediate college writing course (sophomore and junior level) called Rhetoric, Writing, and Culture. Instructors could put their own spin on the course, and my approach was inspired by my initial reactions to Eggers' book. The final project was designed to produce a textual analysis essay in which students would apply the secondary sources I assigned as course readings - theory and background on refugee experience - to primary sources students would research on their own using library research tools, particularly in relation to populations of refugees we had not discussed in class. As a composition and rhetoric teacher-scholar, I had conducted fieldwork on literacy in refugee communities and saw some of the volunteers relying on the above tropes - sometimes engaged in what Teju Cole (2012) has called the "White Savior Industrial Complex." For my research writing, a global perspective meant an understanding of how global forces shape refugee experience alongside audience expectations of depictions of those experiences. Forces in this case are wide-ranging. They are political, military, economic, cultural, and historical, and they come from a diverse set of actors, like international organizations, nation-states, and the public sphere. Audiences can likewise include diverse perspectives. They could be aid workers, volunteers, teachers, or readers and viewers of refugee narratives - united perhaps by a sympathizer/survivor paradigm (to borrow the words of the narrator in What is the What). Scholarship that informed my initial thinking about this assignment was interdisciplinary in nature. For example, in refugee studies, Liisa Malkki (1996) has observed how refugees can be constructed as "speechless emissaries," or objects of aid who are repeatedly denied voice and agency (p. 392). In composition, or English studies more broadly, very little has been written on using refugee narratives in a classroom setting. The act of reading, however, has often been thought of as a way to foster a sense of empathy (Jurecic, 2011). By drawing on my own research interests for this course, I hoped to use refugee narratives as prompts for cultivating a global perspective with students.

Initially, I relied on the definition of a global perspective that I had developed for my research - an understanding of global forces; however, after teaching this assignment, it became clear that the goal of understanding a global perspective can be fraught with multiple meanings that I had not fully accounted for (or understood myself) at the time. So, a few central questions persist throughout this reflection: What is a global perspective? Does it include cultural awareness? An understanding of empathy? A 
degree a critical self-reflection? Have I been using refugee narratives in sound, ethical ways? Has my own suspicion of audience expectations excluded readers who might have had some sort of refugee experience themselves, or who had been subject to those same expectations? These questions do not have concrete answers. Instead, they seem to encourage a reflective stance toward the use of refugee narratives.

Rhetoric, Writing, and Culture was a course broadly conceived to satisfy several general education outcomes. Since the discourses of many universities have adopted a global vocabulary, I saw an opportunity to include my own research interests. For example, the department's outcomes for this course included "knowledge of human cultures" and "intercultural knowledge and competence." Another asked students to "empathize with those who are different than they are." Also, this course was often taken by education majors because it not only satisfied general education requirements in oral and written communication, but it also met the education department's emphasis on diversity and "continuous critical self-reflection." As discussed above, these were concepts I had been grappling with in my own reading of refugee narratives and thought I could make a clear connection by assigning these texts to students.

Students at this urban, mid-sized, Midwestern university were predominantly (though not exclusively) white, middle- and working-class, and from rural and suburban areas of the state. Many of the students in my class fit this profile, though several students were women of color who had attended the local, public high schools. In addition to education majors, some students were studying English literature, and a few were pursuing a degree in international studies. Although I cannot say how demographic factors informed their reading, I designed the course with a suspicion towards a "Western" point-of-view. This constituted a bias on my part based on my research, and a limitation of this assignment is that my suspicion took the Western perspective for granted. I assumed that students would be influenced by cultural assumptions similar to those critiqued in stories about the Lost Boys of Sudan, such as What is the What, and that they were used to constructing refugees according to a donor-recipient paradigm. Though my assumption turned out to be true, teaching this course and reading the student writing made me think more critically about what kind of audience I should be imagining. For instance, what if I had students in the course who themselves had experienced state violence or displacement in some way? How could I make sure they felt invited to share their experiences in writing, question dominant narratives, and at the same time, not feel like they were being singled out? As I continue to work on integrating refugee narratives into my teaching, I want to continue to expose students to global events, but also want to revise this idea of suspicion. Instead of a distrust of readers, perhaps a suspicion of the larger systems of displacement and resettlement could be more apparent.

But, as I said, I was wary of readers' responses to refugee narratives, and I wanted to explore this suspicion with students by having the class reflect on our responses to the assigned readings. This assignment represents the culmination of those efforts. Assigned readings included stories about refugee experience such as What is the What as well as War Child: A Child Soldier's Story by Emmanuel Jal (2009), Outcasts United: An 
American Town, a Refugee Team, and One Woman's Quest to Make a Difference by Warren St. John (2009), and a New Yorker article titled "The Asylum Seeker" by Suketu Mehta (2011). To varying degrees, these texts describe war, displacement, child soldier conscription, refugee camps, learning English, and resettlement in the U.S. Alongside these narratives, students were assigned secondary sources on "the ideal refugee figure" (Malkki, 1996), definitions of "childhood" and "agency" in relation to child soldiers (Rosen, 2007), how the idea of "Africa" is constructed according to Western perceptions (Ferguson, 2007), and the self-Other relationship (Trinh, 2004). To provide students with concrete strategies for analysis, we practiced methods of close-reading by using Jane Gallop's (2000) essay, "The Ethics of Reading: Close Encounters" and rhetorical analysis by reading portions of Gerard Hauser's (2002) Introduction to Rhetorical Theory. As Maureen Moynagh (2011) has observed, close attention to memoir can "challenge the way humanitarian testimony, however unwittingly, reasserts inequality between witness and victim" (p. 45). Through these approaches, we attempted to identify bias as well as alternate perspectives in the stories we read.

Assigned texts were engaged through student-led class discussion in which students would craft open-ended questions. They were also asked to compose weekly, low-stakes response essays that were checked off rather than graded. In these responses, students chose passages from the texts to which they would apply the methods of rhetorical analysis and close-reading. I gave feedback in the form of end comments that posed questions and pointed them toward ideas for further development (or term paper topics). The purpose of this work being "low stakes" was to afford students time and space to reflect on the politics of reading and their relationship to the text.

The transition from discussion and low-stakes writing to the kind of critical reflection asked for in the final project proved difficult, however. The final project asked students to first research "representations of refugee experience" that we had not covered in class. They would then apply a "theoretical approach" from our secondary sources to "analyze the representations" they found. This first part of the project was intended to have students produce a text that they could reflect on. This would be a formal essay that focused on textual analysis and used methods of close-reading and rhetorical analysis to apply specific ideas from course readings to visual and textual representations of a specific refugee community. I told students that a "primary source" in this case could be defined broadly to include newspaper articles, memoirs, fiction, visual images (photographs, websites), film, or other artifacts that depicted the community they were researching. The assignment prompt states that students "must use some sort of theoretical approach and/or reading strategy to help you analyze these representations." Though I communicated my expectations more specifically during class discussion, this kind of analysis would necessarily involve identifying stereotypes, tropes, symbols, or dominant narratives, especially given that the secondary sources we read emphasized representation as an important aspect of understanding the power dynamics of refugee experience.

The second part of the project asked guiding questions like, "What responsibility does 
the reader/viewer have when consuming stories of refugee experience?" and "If your impulse is to feel sympathy, pity, empathy toward the people in these stories, then why, and more importantly, where do these impulses come from?" I intended to point students back to their own writing. But again, this transition had varied results. For example, one student chose to draw on her other courses in education and focused on the theme of education in Africa. And, even though we read Ferguson's chapter on how the idea of Africa is too-often over-generalized, this student relied on monolithic terms, even while questioning "Western" assumptions:

Many Americans believe that African children are unintelligent. This stereotype is inaccurate because most Africans pursue a secondary education. Often times our stereotypes limit the visibility of the few success rates that are in the African Education system.

Although statements like this signal a reflection on presumptions, the writer does not necessarily reflect on her own perspective. By stating that there are "few success rates" in the seemingly homogenous idea of the "African Education system"-capitalizing the words "African Education" - the student reproduces some of the stereotypes she wishes to critique. I believe the student's identification of beliefs about children to be successful, but it is then undercut by the generalization about education.

At times, students reflected on their own reader responses, but in ways that included contradictory statements. For example, one student wrote:

The saying "out of sight out of mind" fits this perfectly because usually only when I am doing something that relates to this English class is the only time I am thinking about the refugees and their stories ... As readers we are limited to only make assumptions about the characters based on how the narrative is written.

I consider this passage a successful reflection on the relationship between the self and the world because of the way the writer considers her difficulties with reading stories about refugee experience. Many times, though, statements like this were undercut by a reproduction of other assumptions. For instance, later in her project, this same student wrote, "I feel compassion for these people, because of their challenges and heartache, but I know they are much stronger individuals than prior to becoming refugees." She identifies her feelings, but does not necessarily unpack them, and she instead reproduces a trope that invokes perseverance while rendering refugees as somehow not being as "strong" before their displacement.

The subject of refugee experience is complicated, so it makes sense that responses are sometimes contradictory. After having done more research on theories of displacement and governance, I have come to see contradiction as an important opportunity for reflection, and even perhaps, resistance to the status quo. That is, as Aihwa Ong (2006) observes, contradiction can signal important inroads for "unexpected possibilities and resolutions" (p. 17). Being attuned to contradictory moments in both class discussion and student 
writing might have enabled the class to compose more pointed reflections.

The final project did not leave me with a clear means of assessing reflective work. I emphasized rhetorical analysis and close-reading as I had with other writing tasks for the course. If students provided specific details and examples, then I saw them as meeting - though not necessarily exceeding - the outcomes of the course, especially those that emphasized "intercultural knowledge and competence." In terms of teacher selfassessment, as I look back on how I might better scaffold critical reflection on the part of the reader, I think about how I defined a global perspective at the start, how my understanding changed having taught this course, and what revisions I would make going forward. If a global perspective was defined more in relation to my research agenda when I designed this course - as an understanding of global forces - now I think more in terms of process, of how contextual knowledge is one component of a global perspective on understanding the "Other." Therefore, one revision I would make to a course like this would be to make better use of the low-stakes writing. Although I would not drastically alter the prompts for low-stakes writing - I still want to emphasize rhetoric and close-reading - I would "close the loop," so to speak, and use weekly responses as artifacts for future analysis. In their final project, students could do a more careful reflection on the writing they produced throughout the term. This, I think, would have them engaged in understanding their own presumptions about the course texts, whatever they might be (so-called "Western" or otherwise).

I was very happy to read in student course evaluations that they found the chosen readings extremely relevant. Several students also said they valued being asked to use specific methods of analysis like rhetorical analysis and close-reading. And, a few of them mentioned that they appreciated the opportunity to do research outside of class because some of their own communities had been host to resettled refugee populations, and they were able to learn more about people they had sometimes volunteered to help. Even if student writing did not express the kinds of reflection I had hoped for, students still seemed to reflect on their roles as readers, but perhaps in ways that were less visible. How to make these ideas more useful in the scaffolding of this assignment is one goal I have for the next iteration.

Teachers outside of writing studies might take up this kind of assignment, one that positions readers alongside texts that represent human suffering, displacement, and humanitarian aid. Several of my colleagues in disciplines like geography and sociology, for instance, have suggested that students could work with texts from a more local perspective. Stories of displacement during Hurricane Katrina (in which another Dave Eggers novel, Zeitoun (2010), is set) could be read in relation to memoirs of global refugee resettlement in order to prompt discussion about representations of displacement in different contexts. In this way, a course that seeks to foster a global perspective could adopt a wide variety of content. Displacement itself could include environmental displacement or economic hardships. And though a global perspective can have multiple meanings, I now think it should emphasize a shared sense of self-reflection. We should approach the content we assign with a degree of suspicion in terms of how people respond 
to it, but also with a degree of suspicion toward our own biases as teachers.

\section{Assignment: Refugee Narratives and the Rhetorics of Global Mobility}

See the Supplementary Files for this article at thepromptjournal.com for a PDF facsimile of the original formatting of this assignment.

\section{Final Project Guidelines}

Your final project asks you to do some outside research and find representations of refugee experience that you can analyze in relation to the many ideas that we have talked about this semester.

Like the first two papers, you must use some sort of theoretical approach and/or reading strategy to help you analyze these representations. This time, though, you need to examine representations beyond the Lost Boys of Sudan. You might examine Hmong experiences in Wisconsin, or other populations in Kakuma refugee camp, the Lost Girls of Sudan, Hurricane Katrina survivors, etc. Essays, stories, novels, poetry, photographs, comics, music, film - all are possibilities for this project. Be creative with the representations you use, but make sure to apply the ideas from class directly to these examples. Remember to show evidence through direct quotation, images, etc. You may analyze these representations in relation to the stories of the Lost Boys, but your analysis should focus on the representations you found for this project and on creating new ideas that can add to what we discussed in class.

The emphasis on reflection here is much greater than in the previous essays. As you read, write, and analyze according to the above suggestions, I want you to also consider and respond to the following questions:

What responsibility does the reader/viewer have when consuming stories of refugee experience? How have you tried to account for this responsibility in your own writing? What positions of privilege do you have as a reader and writer in this class in relation to the people, cultures, and experiences that you are writing about? If your impulse is to compare your life to someone else's, then why is that? If your impulse is to feel sympathy, pity, empathy toward the people in these stories, then why, and more importantly, where do these impulses come from?

These are difficult questions to answer, but it is what I will be looking at most closely as I read your final project. 


\section{References}

Barnett, M., \& Weiss, T. G. (2008). Humanitarianism: A brief history of the present. In M. Barnett \& T. G. Weiss (Eds.), Humanitarianism in Question: Politics, Power, Ethics (pp. 1-49). Ithaca: Cornell University Press.

Boltanski, L. (1999). Distant suffering: Morality, media and politics. Cambridge, UK: Cambridge University Press.

Chouliaraki, L. (2006). The spectatorship of suffering. London, UK: Sage Publications.

Cole, T. (2012). The white-savior industrial complex. The Atlantic. Retrieved from https://www.theatlantic.com/international/archive/2012/03/the-white-saviorindustrial-complex/254843/

Eggers, D. (2007). What is the what. New York: Vintage.

Eggers, D. (2010). Zeitoun (Reprint edition). New York: Vintage.

Ferguson, J. (2007). Global shadows: Africa in the neoliberal world order. Durham N.C.: Duke University Press.

Gallop, J. (2000). The ethics of reading: Close encounters. Journal of Curriculum Theorizing, 16(3), 7-17.

Hauser, G. A. (2002). Introduction to rhetorical theory (2nd ed.). Long Grove, IL: Waveland Press.

Jal, E. (2009). War child: A child soldier's story. New York, NY: St. Martin's Press.

Jurecic, A. (2011). Empathy and the critic. College English, 74(1), 10-27.

MacDonald, M. T. (2015). Emissaries of literacy: Representations of sponsorship and refugee experience in the stories of the lost boys of sudan. College English, 77(5), 408-428.

Malkki, L. H. (1996). Speechless emissaries: Refugees, humanitarianism, and dehistoricization. Cultural Anthropology, 11(3), 377-404.

Mehta, S. (2011). The asylum seeker. The New Yorker. Retrieved from http:// www.newyorker.com/magazine/2011/08/01/the-asylum-seeker

Moynagh, M. (2011). Human rights, child-soldier narratives, and the problem of form. Research in African Literatures, 42(4), 39-59. http://doi.org/10.2979/reseafrilite.42.4.39

Ong, A. (2006). Neoliberalism as exception: Mutations in citizenship and sovereignty. Durham, N.C.: Duke University Press.

Rosen, D. M. (2007). Child soldiers, international humanitarian law, and the globaliza- 
tion of childhood. American Anthropologist, 109(2), 296-306. http://doi.org/10.1525/ AA.2007.109.2.296

St. John, W. (2009). Outcasts united: An American town, a refugee team, and one woman's quest to make a difference. New York, NY: Spiegel \& Grau.

Trinh, T. (2004). Not you/like you: Post-colonial women and the interlocking questions of identity and difference. In S. K. Foss, K. A. Foss, \& C. L. Griffin (Eds.), Readings in feminist rhetorical theory (pp. 215-219). Thousand Oaks, CA: Sage Publications. 